\title{
Diagnóstico de HPV: o processo de interação da mulher com seu parceiro
}

\author{
HPV diagnosis: woman's process of interaction with her partner
}

Diagnóstico de HPV: proceso de interacción de la mujer con su pareja

\section{Octavio Muniz da Costa Vargens', Carla Marins Silva', Gulnar Azevedo e Silva", Vânia Reis Girianelli"' \\ ' Universidade do Estado do Rio de Janeiro, Faculdade de Enfermagem, Programa de Pós-Graduação em Enfermagem. Rio de Janeiro-RJ, Brasil. \\ "Universidade do Estado do Rio de Janeiro, Instituto de Medicina Social, Departamento de Epidemiologia. Rio de Janeiro-RJ, Brasil. \\ "' Secretaria Municipal de Saúde e Defesa Civil do Rio de Janeiro. Rio de Janeiro-RJ, Brasil.}

\author{
Submissão: 25-02-2011 Aprovação: 18-04-2013
}

\section{RESUMO}

Pesquisa descritiva, com abordagem qualitativa, que objetivou analisar o processo de interação da mulher com seu parceiro a partir do diagnóstico de infecção pelo papilomavírus humano (HPV). Foi realizada em treze comunidades dos municípios de Duque de Caxias e Nova Iguaçu, Estado do Rio de Janeiro, de outubro/2006 a setembro/2008. Foram entrevistadas 20 mulheres com diagnóstico de infecção pelo HPV de alto risco oncogênico. Os pressupostos do Interacionismo Simbólico e da Grounded Theory nortearam a coleta e análise dos dados. Os resultados revelaram que o diagnóstico do HPV significa sérios desafios no relacionamento das mulheres com seu parceiro principalmente no que se refere à adoção de medidas preventivas. Conclui-se que estas questões indicam a necessidade de um atendimento humanizado que favoreça o empoderamento das mulheres.

Descritores: Saúde da Mulher; Enfermagem; Doenças Sexualmente Transmissíveis.

\begin{abstract}
This is a descriptive research, with qualitative approach, which aimed at analyze the interaction process between woman and her partner starting from the diagnosis of infection by the human papilomavirus (HPV). It was accomplished in 13 communities in the cities of Duque de Caxias and Nova Iguaçu, Rio de Janeiro state, Brazil, from October/2006 to September/2008. Twenty women, diagnosed with HPV infection related to oncogenic high risk, were interviewed. The Symbolic Interactionism and Grounded Theory perspectives guided data collection and analysis. The results revealed that the HPV diagnosis means serious challenges in the women's relationship with her partner mainly regarding to the adoption of preventive initiatives. It is concluded that these issues lead to the need of a humanized care in order to favor the women's empowerment.
\end{abstract}

Key words: Woman's Health; Nursing; Sexually Transmitted Diseases.

\section{RESUMEN}

Investigación descriptiva, cualitativa, que objetivó analisar la interacción de la mujer y su compañero a partir del diagnóstico de infección por papiulomavirus humano (HPV). La investigación fue realizada en 13 comunidades de las ciudades de Duque de Caxias y Nova Iguaçu, estado de Rio de Janeiro, Brasil, de Octobre/2006 a Septembre/2008. Se entrevistaran veinte mujeres con diagnóstico de infección por HPV relacionado a alto riesgo oncogénico. Los principios del Interacionismo Simbólico y de la Grounded Theory nortearan la colección y análisis de datos. Los resultados revelaron que este diagnóstico significó serios desafíos en la relación de la mujer con su compañero principalmente con respecto a adopción de medidas preventivas. Se concluye que estos questiones Ilevan a la necesidad de un cuidado humanizado para favorecer el empoderamiento de las mujeres.

Palabras clave: Salud de las Mujeres; Enfermería; Enfermedades de Transmisión Sexual. 


\section{INTRODUÇÃO}

O câncer do colo do útero permanece como uma importante causa de morbidade e mortalidade na população feminina em todo mundo, embora possa ser curado se detectado precocemente. No Brasil, em 2002, a taxa de mortalidade por câncer de colo do útero foi de 5,03 por 100.000, sendo esta a quarta causa de óbito entre as mulheres. Estimativas do Instituto Nacional do Câncer (INCA) indicam que, em 2012, ocorreram cerca de 17.540 casos novos, com taxa estimada de $17 \mathrm{ca}$ sos a cada 100.000 mulheres. De acordo com a incidência por regiões no Brasil, sem considerar os tumores de pele não melanoma, o câncer de colo de útero ocupa a primeira posição na região norte (24/100 mil). Nas regiões Centro-Oeste (28/100 mil) e Nordeste (18/100 mil) se encontra em segundo lugar em incidência; na região Sudeste (15/100 mil), ocupa a terceira posição, e na região Sul (14/100 mil), a quarta posição(1).

Na última década, a infecção pelo papilomavírus humano (HPV) por tipos de alto risco oncogênico tem sido reconhecida como uma causa necessária para desenvolvimento do câncer do colo do útero ${ }^{(2-4)}$. O HPV é transmitido principalmente por via sexual através do contato direto com a pele ou mucosa infectada. As lesões, quando presentes, são contagiosas e em alguns casos o uso do preservativo, por si só, não assegura proteção. No entanto, embora estas lesões possam ser assintomáticas e transitórias, algumas mulheres desenvolvem infecções persistentes e que podem resultar em lesões precursoras do câncer do colo do útero ${ }^{(5)}$.

Diante disto, o objeto desta pesquisa foi o processo de interação da mulher com seu parceiro a partir do diagnóstico de HPV. Considerando que o significado é construído pelo indivíduo a partir de um processo de interação social e este expressa a síntese conceitual e prática das dimensões políticas e sociais ${ }^{(6)}$, compreender e interpretar o significado atribuído pela mulher ao diagnóstico de HPV é uma ferramenta fundamental para o planejamento e avaliação das ações de saúde.

Assim, definiu-se como objetivo analisar o processo de interação da mulher com seu parceiro a partir do diagnóstico de HPV.

\section{METODOLOGIA}

Trata-se de pesquisa com abordagem qualitativa, considerando a natureza subjetiva do objeto de estudo. Foi realizada em treze comunidades dos municípios de Duque de Caxias e de Nova Iguaçu, no estado do Rio de Janeiro, no período de outubro/2006 a setembro/2008. A escolha deste cenário se deu em função da ocorrência da infecção pelo HPV em mulheres que ali habitam e que tiveram acesso ao exame de captura híbrida para rastreamento de câncer de colo do útero, no ano de 2002, registradas através de estudo prévio ali realizado $^{(7)}$. Os sujeitos da pesquisa foram selecionados entre as mulheres que participaram deste estudo anterior ${ }^{(7)}$ e tiveram diagnóstico de infecção pelo HPV dos tipos relacionados ao alto risco oncogênico, e que eram assintomáticas.

A constituição do grupo amostral foi definida no decorrer do estudo em função do processo de análise comparativa constante, característica da Grounded Theory ${ }^{(8)}$. O quantitativo total de mulheres foi determinado com base no critério de saturação teórica ${ }^{(9)}$.

Para este estudo, como estratégia de coleta de dados, utilizou-se a entrevista semi-estruturada, o que permitiu ao entrevistador utilizar um guia de tópicos para garantir que todas as áreas das questões fossem cobertas ${ }^{(10)}$. Como ponto de partida para estas entrevistas empregou-se uma pergunta sobre significado atribuído pela mulher ao diagnóstico de infecção pelo HPV no contexto de rastreamento para câncer do colo do útero. As entrevistas foram gravadas em equipamento midiaplayer MP4 e posteriormente transcritas para análise de dados, cujo processo baseou-se nos pressupostos teórico-metodológicos do Interacionismo Simbólico ${ }^{(6)}$ e da Grounded Theory ${ }^{(8)}$.

Sintetizando as idéias centrais do Interacionismo Simbólico, a sociedade é uma instituição composta por pessoas e grupos em constante interação. Esta interação tem como alicerce o compartilhamento de sentidos sob a forma de compreensões e expectativas comuns. Este processo interativo é dinâmico, variando de acordo com as diferentes situações que são enfrentadas. Estas situações são percebidas de forma seletiva, de acordo com as necessidades, que por sua vez são definidas a partir dos sentidos que as coisas têm para as pessoas, e que são derivadas da interação(11).

De acordo com a Grounded theory, a análise comparativa constante dos dados indica que novos grupos amostrais devem ser incluídos e, dessa forma, que novos conjuntos de dados devem ser obtidos. Por esse método há um ir e vir entre a coleta e a análise, em que as informações são analisadas sistemática e simultaneamente à coleta ${ }^{(12-13)}$ :

$\checkmark$ codificação aberta ou codificação substantiva, realizada com todos os dados após cada coleta, em que os dados são analisados linha por linha e com a atribuição de códigos, mantendo-se os termos que foram utilizados pelos sujeitos do estudo;

$\checkmark$ categorização provisória, em que os códigos substantivos são agrupados observando-se as similaridades e diferenças conceituais e, nessa fase, não são considerados o assunto ou o tema tratado, apenas os conceitos relevantes que parecem pertencer a um mesmo fenômeno;

$\checkmark$ codificação teórica ou categorização, momento em que, definidas as categorias emergentes dos dados, serão estabelecidas as inter-relações entre estas, consideradas suas subcategorias;

$\checkmark$ codificação seletiva, quando há a descrição do Processo Social Básico, desencadeando a Categoria Central que é o elo entre todas as categorias.

Foram atendidas todas as exigências preconizadas pelo Conselho Nacional de Saúde, tendo sido o projeto avaliado pela Comissão de Ética em Pesquisa da Universidade do Estado do Rio de Janeiro (UERJ) e aprovado sob Protocolo nº31/2007.

\section{RESULTADOS}

Os dados revelaram o processo de interação da mulher com o parceiro desde o diagnóstico de HPV relacionado ao 
tipo de alto risco oncogênico até a conscientização e enfrentamento da nova situação.

A partir do diagnóstico do HPV e conhecendo a sua forma de transmissão, a mulher inicialmente nega a situação de portadora da doença e busca argumentos que reforcem a impossibilidade de ter adquirido a doença. Utiliza argumentos mais subjetivos expressando: saber como ela vive, com quem ela vive e que saberia se estivesse doente, ou ainda se seu parceiro estivesse doente.

Porque eu pensei assim: "eu sei como eu vivo, com quem eu ando", entendeu?... E quando você tem uma coisa, você sente que você está sentindo alguma coisa, entendeu? (E01)

\section{Como, se eu só vou com meu marido? (E06)}

Posteriormente, a mulher lança mão de argumentos mais racionais, relacionados ao processo de transmissibilidade da doença, muitas vezes recém aprendidos, como o uso de preservativo durante as relações sexuais.

Eu falei: 'é impossível, eu não'. Eu falei assim: 'é impossível, pois eu estou usando a camisinha [...] que agora eu só uso camisinha, não vou com ele sem camisinha'... Por isso que eu falo 'desse não foi que eu peguei'. (E03)

No processo de conscientização, a mulher se reconhece como portadora do HPV e que o parceiro está, direta ou indiretamente, relacionado a essa nova situação. Neste momento a mulher vivencia outro conflito, revelar ou não ao parceiro sobre a sua situação.

Ao decidir não comunicar ao parceiro, busca argumentos para justificar a sua decisão, tais como: não se sente à vontade para abordar o tema, encontra-o poucas vezes durante a semana e têm diversos outros assuntos para conversar.

Ah! Mais ou menos. Porque eu só vejo ele em final de semana, e quando eu vejo, eu nem falo sobre isso não, eu não falo. Não contei não, não parei para conversar com ele não. [...] chegar assim e conversar? Ai, não gosto não. (E02)

No entanto, percebe a necessidade de usar preservativo e exige o uso do mesmo alegando não poder ter relação sexual desprotegida por ordem médica, sem explicar o real motivo.

Só falo que tem que colocar a camisinha, tem que botar... A médica mandou botar... Porque não pode e que tem que usar e pronto. É isso (E11).

As mulheres enfrentam a sua dificuldade e decidem comunicar ao parceiro da sua situação e que há necessidade de usar preservativo. Vale destacar que elas só utilizam preservativo devido ao problema atual.

Pelo problema que eu tive, aí só uso camisinha. (E14).
Após superar suas dificuldades para informar ao parceiro, a sua situação de portadora do HPV, tem que enfrentar a reação do mesmo que, geralmente, não a apóia. O parceiro não acredita na possibilidade de ter a doença, reage de forma grosseira, e a acusa de traição.

O parceiro acha impossível ter a doença, negando a situação apresentada, pois se cuida e usa preservativo, sendo este problema somente dela.

Meu marido dizia que ele se cuidava direitinho e o problema é que apareceu em mim. (E08)

Ele ficou assim: 'como? Comigo? A gente só vai com camisinha!'(E03)

O parceiro reage de forma grosseira ou não dando importância para o problema. Nega a situação apresentada, o que dificulta sua compreensão.

Porque tem homens que são machistas, que não querem saber. Meu marido foi, no primeiro dia, grosso, estúpido, né? 'Ah!, que isso é uma palhaçada, que não sei o que mais!'. (E12)

E ficava falando aquela coisa toda dele, né? "[...]" e ficava com aquela estupidez dele, dizendo assim: 'ah, isso é besteira, isso é só invenção desse povo'. (E02)

Neste processo de discussão, o parceiro acusa a mulher de traição, projetando nela toda a culpa da situação vivenciada.

Ele disse: 'Ah, não! Você me traiu com outro. (Já que eu trabalho fora...) você está é com outra pessoa'... não sei que lá. "[...]" Aí, ele falou: 'é por isso mesmo, duvido que você não está com algum médico desses de lá.. (E04)

A dificuldade de relacionamento vivenciada, neste período, dificulta a compreensão e adesão ao tratamento por parte do parceiro. Este não aceita ter relações sexuais com preservativo e não adere às demais orientações.

Aí, meu esposo, ele não aceita transar de camisinha, meu primeiro marido. Aí, ficou aquilo... (E09)

Frente às acusações e dúvidas, sobre a sua conduta e ao diagnóstico, a mulher tenta contra-argumentar a seu favor, explicando como descobriu e convidando o parceiro a participar dos atendimentos. Como conseqüência a mulher acaba vivenciando brigas em casa e deixa de fazer atividades que possam justificar as acusações, como por exemplo trabalhar fora. Ela continua tentando pedir apoio ao parceiro, mas, geralmente, sem sucesso, o que leva, muitas vezes, à separação.

Aí, eu disse assim: 'poxa, você que tem que me dar o apoio!'. Nos separamos, que a gente teve muita briga. Ele não quis aceitar muitas coisas, né? Teve muitas brigas e nos separamos. (E01) 
Agora eu não trabalho mais fora. Mas antigamente eu trabalhava fora, saía 4 horas da manhã e só chegava 8. (E16)

Ainda bem que eu convidei ele para ir, “[...]” eu dizia: 'não, não é isso não. Você pode até ver, foi uma campanha que eu fiz'. Mostrei os exames, eu mostrei o hospital, eu mostrei a doutora que eu estava consultando, a doutora..., eu esqueci o nome dela, está aí no carimbo também. (E04)

Meu marido, que esse daqui é do meu segundo casamento, "[...]" Hoje, eu já sou casada pela segunda vez, né? Não, ele é uma pessoa legal pra caramba. (E07)

A mulher, apesar dos problemas vivenciados, tenta justificar a reação do parceiro como natural. Reconhece o predomínio da concepção machista de relacionamentos. Acrescenta ainda o fato de serem homens jovens e por isso não aceitam o uso do preservativo nem o tratamento. Tal situação evidencia o maior poder do homem na relação.

Porque tem homens que são machistas, que não querem saber, "[...]" Que ele é mais jovem que eu, e ficava com aquela estupidez dele. (EO2)

Normalmente não parte da mulher, parte do homem querer ter filho. Da mulher é meio difícil, a não ser que o casamento seja um mar de rosas, aí sim, mas quando não é? É muito difícil. A maioria dos casamentos hoje é por conveniência. (E05)

\section{DISCUSSÃO}

O processo de descoberta de si como portadora de HPV afeta de alguma forma a relação com o parceiro. Considerando as relações de gênero, em especial as características do gênero feminino, verifica-se que a vulnerabilidade em relação às Doenças Sexualmente Transmissíveis (DST) cresce a cada dia, pois as mulheres, muitas vezes, não conseguem perceber a existência do risco para contrair uma DST. Este dado pode ser encontrado em um estudo realizado com mulheres na cidade de Pelotas, RS, em que $64 \%$ das mulheres achavam impossível ou quase impossível contrair este tipo de doença ${ }^{(14)}$.

Na presente pesquisa, quando as entrevistadas negam a doença, utilizam argumentos subjetivos para expressar esta situação, afirmando conhecer seu parceiro e como elas vivem, enfocando que fazem parte de um relacionamento estável. As mulheres se consideram em relacionamento estável em função das características ou comportamentos que reconhecem em seus parceiros, advindos do fato de conhecê-los, como, por exemplo, estar sempre presente e o fato do parceiro ser uma boa pessoa ${ }^{(15-16)}$.

Algumas mulheres colocam o "conhecer o parceiro" como organizador do seu relacionamento, dentro do seu mundo afetivo e amoroso. A categoria "conhecer" estrutura as relações sociais e sexuais, garantindo segurança, aproximação e aumento da intimidade ${ }^{(15)}$. E nas entrevistas de um estudo sobre o significado da fidelidade para homens casados, surgiu a importância de valorizar a pessoa que está sempre ao lado buscando o mesmo ideal ${ }^{(17)}$.
Em seguida, a mulher busca argumentos mais consistentes para a negação da doença, relacionados ao processo de transmissibilidade da doença, muitas vezes recém-aprendidos, como o uso de preservativo durante as relações sexuais. Vale ressaltar que o número de mulheres que utilizam preservativos em todas as relações sexuais é muito pequeno. Em um estudo sobre vulnerabilidade às doenças sexualmente transmissíveis entre mulheres com alta escolaridade apenas $23,3 \%$ declararam manter relações com proteção sempre $^{(18)}$.

Quando a mulher se conscientiza de que é uma portadora do HPV, ela reconhece que o parceiro está relacionado de alguma forma com esta nova situação. Nesta ocasião a mulher decide se revela ou não ao seu parceiro sobre o diagnóstico positivo.

Em pesquisa sobre o comportamento preventivo com relação às DST de estudantes universitários de comunicação social de São Paulo, verificou-se a existência distintos padrões de comportamento com relação ao parceiro, em que 56\% optou pela comunicação e divisão do problema com o parceiro. A ocorrência de problemas na saúde sexual e reprodutiva e a observação de quase $20 \%$ de omissão adotado com os parceiros chamam a atenção, pois as mulheres não desejam correr o risco de perder o namoro e suas atividades sociais ${ }^{(19)}$.

No presente estudo, a mulher, ao resolver que não vai comunicar ao parceiro, justifica a sua decisão dizendo que não se sente à vontade para abordar o tema, encontra-o poucas vezes durante a semana e têm diversos outros assuntos para conversar. Porém, ela percebe a necessidade do uso do preservativo e negocia seu uso, mesmo sem dizer o verdadeiro motivo. E como o uso do preservativo está na condição de negociação, muitas vezes as relações de poder não permitem que a mulher faça valer suas vontades. A necessidade de usar o preservativo masculino gera conflitos interpessoais, resultantes de duas vontades, e isto é uma questão central para a diminuição da transmissão sexual do vírus da imunodeficiência adquirida - $\mathrm{HIV}^{(20)}$. A negociação do sexo seguro muitas vezes é considerada uma "batalha" entre homens e mulheres, e a mulher, que opta por não informar seu diagnóstico ao parceiro, deve resistir e se impor sem um argumento real.

E aquelas que, apesar da dificuldade, decidem comunicar ao parceiro da sua nova situação, percebem que existe a necessidade de usar preservativo e busca a negociação. Em uma pesquisa sobre a autopercepção de mulheres quando a vulnerabilidade para contrair DST/HIV ${ }^{(15)}$, algumas mulheres entrevistadas passaram a usar preservativo após descobrir que tinham uma DST, e somente por esse motivo.

Quando ela comunica a nova situação, ela precisa lidar com a reação do parceiro que, normalmente, é uma reação negativa e não a apóia. O parceiro nega a situação apresentada, alegando ser somente problema da mulher. Ele reage de forma grosseira, e a acusa de traição. A reação do parceiro gera uma preocupação, pois o HPV é uma doença sexualmente transmitida e a questão da fidelidade aflora e ocorre um questionamento da conduta sexual ${ }^{(21)}$ e a exigência da mulher para o uso do preservativo, faz com que o homem interprete como infidelidade da mulher ${ }^{(16)}$. 
Diante desta situação, a mulher não recebe apoio durante o tratamento e ainda não consegue negociar o sexo seguro. Sabe-se que a adesão ao tratamento de uma DST deve ser vista como uma atividade conjunta com o parceiro, que nem sempre concorda em participar. Em um estudo sobre a extensão do pré-natal ao parceiro ${ }^{(22)}$, a abordagem do companheiro durante a gravidez no controle das DST é um dos principais problemas existentes. Esta mesma dificuldade se configura em outros setores e também é destacado na presente pesquisa.

Essas situações, quando analisadas sob o olhar dos relacionamentos, as pessoas que têm um diagnóstico de DST enfrentam muitos problemas, como mágoas de um dos parceiros, pela suspeita ou certeza de ter sido enganado ou traído pelo parceiro infectado ${ }^{(23)}$.

Vivendo esta dificuldade, a mulher começa a reagir às acusações do parceiro, tenta fazê-lo participar de sua nova situação de alguma forma, porém as brigas levam a separação do casal. O HPV interfere no relacionamento conjugal, levando a mudança nas atitudes do casal, a não aceitação e por conseqüência a descontinuidade da relação com a separação ${ }^{(22,24)}$.

Neste turbilhão de momentos angustiantes após a revelação do diagnóstico, a mulher tenta justificar a reação do parceiro como natural e esperada. Desta forma, torna-se evidente as relações assimétricas de poder e essas relações desiguais prejudicam desde a negociação do sexo seguro até a acusação de terem adquirido a doença. Sabe-se que a desigualdade entre os sexos, masculino e feminino, tem produzido, historicamente, uma submissão e inferiorização da mulher e isto produz uma condição de vulnerabilidade para contrair uma DST ${ }^{(17)}$

\section{CONCLUSÃO}

Ficou evidente que, para as mulheres, o diagnóstico significa uma série de mudanças em seu relacionamento com o parceiro. A mulher, inicialmente, nega sua situação por conhecer o parceiro e por usar preservativos. Em seguida, ela toma consciência da sua nova situação e precisa enfrentá-la, trazendo sérios desafios à relação. Ela precisa decidir se vai informar ou não o diagnóstico ao seu parceiro. Com isso, vivencia uma experiência de dificuldade para adoção efetiva de medidas preventivas e a reação do parceiro, abalando o relacionamento. Embora nas questões relativas ao exercício pleno e livre da sexualidade, para ambos os sexos, haja necessidade de decisões compartilhadas, estas questões levam à necessidade de uma abordagem multiprofissional humanizada, visando o empoderamento das mulheres para que elas possam decidir sobre sua sexualidade e saúde.

\section{REFERÊNCIAS}

1. Ministério da Saúde [homepage na internet]. Estimativa 2012: incidência de câncer no Brasil [acesso em 22 abr 2013]. Disponível em: http://www.inca.gov.br/ estimativa/2012/

2. Walboomers JM, Jacobs MV, Manos MM, Bosch FX, Kummer JA, Shah KV, et al. Human papillomavirus is a necessary cause of invasive cervical cancer worldwide. J Pathol 1999;189(1):12-9.

3. Franco EL, Rohan TE, Villa LL. Epidemiologic evidence and human papillomavirus infection as a necessary cause of cervical cancer. J Natl Cancer Inst 1999;91:506-11.

4. Bosch FX, Lorincz A, Muñoz N, Meijer CJ, Shah KV. The causal relation between human papillomavirus and cervical cancer. J Clin Pathol 2002;55(4):244-65.

5. World Health Organization [homepage na internet]. WHO/ICO Information Centre on Human Papilloma Virus (HPV) and Cervical Cancer [acesso em 20 jul 2010]. Disponível em: http://www.who.int/hpvcentre/en/

6. Blumer H. Symbolic Interactionism. Perspective and Method. London: University of California Press; 1969.

7. Girianelli VR, Thuler LC, Szklo M, Donato A, Zardo LM, Lozana JA, et al. Comparison of human papillomavirus DNA tests, liquid-based cytology and conventional cytology for the early detection of cervix uteri cancer. Eur J Cancer Prev 2006;15(6):504-10.

8. Glaser BG, Strauss AL. The discovery of grounded theory; strategies for qualitative research. New York: Hawthorne; 1967.
9. Glaser BG. Theoretical Sensitivity: Advances in the methodology of grounded theory. California: Socilogy Press; 1978.

10. Polit DF, Beck CT, Hungler BP. Fundamentos de Pesquisa em enfermagem: métodos, avaliação e utilização. 7. ed. Porto Alegre: Artmed Editora; 2011.

11. Haguette TMF. Metodologias qualitativas na sociologia. Petrópolis: Editora Vozes; 2007.

12. Glaser BG. The Grounded Theory Perspective: conceptualization contrasted with description. California: Socilogy Press; 2001.

13. Glaser BG. Basics of Grounded Theory Analysis. California: Socilogy Press; 1992.

14. Silveira MF, Béria JU, Horta BL, Tomasi E. Autopercepção de vulnerabilidade às doenças sexualmente transmissíveis e Aids em mulheres. Rev Saúde Pública 2002;36(6):670-677.

15. Silva CM, Vargens OMC. A percepção de mulheres quanto à vulnerabilidade feminina para contrair DST/HIV. Rev Esc Enferm USP 2009;43(2):401-6.

16. Rangel TSA, Santos SD, Vargens OMC. Atenção à muIher com soropositividade para o HIV: uma análise na perspectiva da integralidade. Ciênc Cuid Saúde 2010;9(1):137-143.

17. Silva CGM. O significado de fidelidade e as estratégias para prevenção da Aids entre homens casados. Rev Saúde Pública 2002;36(4 Suppl):40-49. 
18. Santos $T L$, Abud ACF, Inagaki ADM. Vulnerabilidade às doenças sexualmente transmissíveis entre mulheres com alta escolaridade. Rev Enferm UERJ 2009;17(4):502-5.

19. Figueiredo R. Comportamento Preventivo com Relação às DST/AIDS de Estudantes Universitários de Comunicação Social de São Paulo. In: Jornadas Universitárias em Saúde: a história de um projeto; 2000 nov; São Paulo, Brasil. Centro Vergueiro de Atenção à Saúde da Mulher e Produção de Materiais Educativos, 2000.

20. Feliciano KVO. Prevenção da Aids entre os jovens: significados das práticas e os desafios à técnica. Rev Bras Saúde Matern Infant 2005;5(4):429-38.
21. Queiroz DT, Pessoa SMF, Sousa RA. Infecção pelo Papiloma Vírus Humano (HPV): incertezas e desafios. Acta Paul Enferm 2005;18(2):190-6.

22. Duarte G. Extensão da assistência pré-natal ao parceiro como estratégia de aumento da adesão ao pré-natal e redução da transmissão vertical de infecções. Rev Bras Ginecol Obstet 2007;29(4):171-4.

23. Passos MRL. HPV: Que Bicho É Esse? 3. ed. Piraí: RQV; 2005.

24. Diógenes MAR, Varela ZMV, Barroso GT. Papillomavirus humano: repercussão na saúde da mulher no contexto familiar. Rev Gaúcha Enferm. 2006;27(2):266-73. 